found a defence of the eecentric Edgar Allen Poe-the first defence of him we happen to have met with. Dr. Gairdner has an article on "Homcopathy." In itself, it is all very satisfactory, but truly it is making that worst of all absurdities of so much consequence, that we had rather the latter had now been left to slumber on in comatose stupidity than thus to find a place in this first series of "Edinburgh Essays" by the side of Plato and the modern Stagyrite Hamilton. The remaining articles are, "Early English Life in the Drama," "Progress of Britain in the Mechanical Arts," "Scottish Ballads," and "Chemical Final Causes," articles, we may state, well worthy the reputation of their respective authors.

\section{ON SOME OF THE EFFECTS PRODUCED BY CARIOUS TEETH.}

\section{To the Editor of The Lavoer.}

SIR,-The perusal in THE LANCET of February 14 th of the interesting practical lecture by Mr. Smith, of Leeds, on the above subject, recalled to my mind three cases somewhat analogous to those related in Mr. Smith's Iecture, which have come under my own notice during the last two years. Their true nature and obvious treatment did not occur to myself, and a statement of them may be useful to some of your readers. The three patients were all young men, between the nges of twenty-five and thirty years, and, curiously enough, they were all affected on the lefi side of the face.

1. R. S-, by occupation a coachnan, footman, \&c., to an old gentleman, called upon me two years ago to get something done for a sore on the centre of his left cheek. He said it had been a boil, which suppurated and broke about two months previously. His face was much swollen, and, as he had to wait at his master's table, it rendered him untit for his work. The patient had consulted another surgeon, and had tried various remedies, but could not gget it healed. Fre was obherwise the picture of health. I thought it might be some chronic affection of the parotid gland, strumous or otherwise. I gave him some zinc lotion to inject into tho opening, and to apply a bit of rag dipped in the swme, and covered with oilech silk. In about three weeks he came to tell me that the sore was healed, but his cheek was swollen. I gave him iodine to apply over it. There was an ugly cicatrix where the sore had been. In the course of mother month the patient came acain, presentin an abscess ready to burst in the old place. I opened it, told him to ponltice it for a few days, and then use the former treatment. In about three months he called again, and told me that after he last saw me, being useless in his situation, he went home to Wlinburgh, where he saw Professor Syme, who gave him something to use, and that the sore did not heal for six weeks after I opened it. The Profescor told him that the sore arose from a wisdom tooth coming up, for which there was not room in the jaw, and advised him, if the sore did not heal, or should trouble him again, to have the adjacent tooth extracted. His face was now much swollen, and an abscess was evidently forming again. I examined his mouth, and saw that he had got the upper wisdom teeth only, and that there was evidently a want of space for those below. I accordingly extracted the second molar tooth, after which the swelling gradually subsided, and the wisdom tooth soon filled up the vacant space. He was now permanently cured.

2. Some months before I saw the last case, R. T-, a forester by occupation, came to me with a large abscess on the left cheek, about an inch above the angle of the jaw. I opened the abscess, and by using poultices for some days, and water dressing afterwards, the sore healed in about two weeks. Shortly after I extracted the tooth from case No. I, I was again visited by No. 2. The abscess was now the same as before; but observing the similarity between the appearance of this case and the former, I examined his mouth, and saw that he still wanted the wisdom tooth in the left lower jaw, for which there was evidently no room, wnd the gum round about was a rood deal inflamed. It so happcned that a year or so before he came to me with the first abscess, I had extracted the second molar tooth in the right lower jaw for toothache, the place of which was now filled up by the wisdom tooth. now extracted the same to th on the left side, when the abscess broke into the moutb, and the wisdom tooth replaced the removed one as before. He has not been troubled since.

3. A. T-, a dealer in tea, consulted me four months ago for a swelling on his cheek. I found that an abscess was forming. The treatment and result were the same as in the other cases, with the important exception that, having recognised the nature of the case before the abscess broke on the cheek, I saved this patient from having an ugly cicatrix, as the other two unfortunately had, and will have as long as they live. I am, Sir, your obedient servant,

Peebles, March, 1857. Robert Crawford, M.D.

\section{MEDICAL REGISTRARS To the Editor of THE LANCET.}

Sir, - I beg, through the medium of your columns, to thank Mr. Edmunds for having called attention to the impropriety of appointing medical practitioners to the office of registrar of births and deaths, and sincerely trust the subject will not be allowed to drop until every medical man who feels himself agrrieved by the misconduct of those officials has spoken out.

If I mistake not, your opinion has always been that medical practitioners ought not to hold these appointments, and I have no doubt that, now the subject has been broached, a mass of evidence will be forthcoming more than sufficient to establish the soundness of your views. It is all very well for your correspondent, Mr. George "Frederick Knipe, to assure us "that there is nothing in the office destructive to that sense of truth and honour which medical men onght to possess ;" and we are bound to assume that, as far as he is concerned, his medical neighbours find it so; but it would have been much more to the purpose if, instead of diverting ns with "crick," "frogs," and "stoppage," he had explained how it happens that so inany medical men have to complain of attempts on the part of medical registrars, to damage them in the estimation of their patients; fathers and mothers tampered with when registering births; doubts as to treatment excited in the minds of relatives or frierds when registering deaths, many instances of which I could mention, but I forbear to trespass on your space. I only hope the subject will be thoroaghly discussed in your impartial journal.

Warch, 1857. I remain, Sir, yours, \&c., No MiedrCaI RegrsmaRs.

\section{To the Editor of THE LAICaT.}

SIR,-As a medicnl registrar for ncarly twenty years, I may perhaps be allowed space in your column for a fow observations upon the subject at issue.

The appointment in the first instance of recistrars of births and deaths was given, I believe, almost miversally to surgeons holding union districts. The fact that there are upwards of 300 names of medical men, in the list published in 1857 , for registrars in England, should, I think, go some way to prove that they are not for from being "the right men in the right place." I have been a subscriber to THE LANCET for abont thirty years, and believe the letter of Mr. J. Edmunds, of Kineton, is the only one that has appeared impugning the professional character of medical registrars. Mr. Edmunds' objeetion is puerile in the extreme, as it would apply with equal force to all certificates of calise of death. Of course, there is no guarantee in any case of a true statement of cause of death being given to the registrar, whether given by himself or others. The lecter of Dr. Goate, in the same number of your journal, goes far to show the utility of medical registrars, as such loose and vague phrases moust, and do often to me, occur as given by ignorant informants as "causes of death."

I beg to inform your correspondent "M.R.C.S., \&c.," of the 14th inst., thas he and his fellow-surgeons have two courses open to them: one, upon well-authenticated facts, to state the case to the Registrar-General, who would, I am certain, remove a registrar who so grossly abused his office; the other being, for medical men thus treated to refuse giving certificates of cause of death, such certificates not being compulsory on them.

There is no office, Sir, that a man can hold which does not render him liable to the carping of the jealous and discontented; but I maintain that while I see the names of upwards of 300 medicil men acting as registrars, with only one accusation in twenty years brought against their professional character, (viz., the letter of "M.R.C.S.,") there cannot be much ground for complaint.

March, 1857. I am, Sir, your obedient servant,

THE Queen has been pleased to appoint Dr. Robert Ferguson to be Physician Extraordinary to Her Majesty. 